\title{
A nicotine patch plus nicotine nasal spray was more effective than a nicotine patch alone for smoking cessation
}

\author{
Blondal T, Gudmundsson LJ, Olafsdottir I, et al. Nicotine nasal spray with nicotine patch for smoking cessation: randomised trial \\ with six year follow up. BMJ 1999 Jan 30;318:285-9.
}

\section{Question}

Is a nicotine patch plus nicotine nasal spray more effective than a nicotine patch alone for smoking cessation?

\section{Design}

Randomised, double blind, placebo controlled trial with 6 years follow up.

\section{Setting}

Reykjavik, Iceland.

\section{Participants}

239 people aged 22-66 years (mean age 42 y, 67\% women) who had smoked $\geqslant 1$ cigarette/day for $\geqslant 3$ years. Exclusion criteria were recent myocardial infarction, severe nasal allergy, skin disease, use of smokeless tobacco, current misuse of alcohol, pregnancy, or lactation. Follow up was $98 \%$.

\section{Intervention}

Participants were allocated to 5 months of nicotine patches at daily dosages of $15 \mathrm{mg}$ for 3 months, $10 \mathrm{mg}$ for the fourth month, and $5 \mathrm{mg}$ for the fifth month, plus 1 year of either a nicotine nasal spray, $0.5 \mathrm{mg} /$ dose $(n=120)$, or a placebo spray $(n=119)$. Group support meetings and individual follow up were provided.

\section{Main outcome measures}

Duration and rate of sustained abstinence from smoking were measured from day 1 of smoking cessation. Abstinence was defined as not taking a single puff of a cigarette, not using other forms of tobacco or nicotine drugs, or a carbon monoxide concentration $<10 \mathrm{ppm}$.

\section{Main results}

Participants who received a nicotine patch plus nicotine nasal spray had higher abstinence rates than those who received a nicotine patch plus placebo spray at 15 days $(\mathrm{p}=0.004), 6$ weeks $(p=0.011), 3$ months $(p=0.045), 6$ months $(p=0.005)$, and 1 year $(\mathrm{p}=0.001)$; and a trend towards a higher abstinence rate at 6 years $(\mathrm{p}=0.08)($ table $)$.

\section{Conclusions}

Use of a nicotine patch for 5 months plus nicotine nasal spray for 1 year was more effective than a nicotine patch alone for smoking cessation. Definite differences in sustained abstinence rates at 1 year persisted as a trend at 6 years.

A nicotine patch plus nicotine nasal spray v a nicotine patch plus placebo spray for abstinence from smoking*

\begin{tabular}{lllcl}
\hline Follow up & $\begin{array}{l}\text { Patch and } \\
\text { nicotine spray }\end{array}$ & $\begin{array}{l}\text { Patch and } \\
\text { placebo spray }\end{array}$ & RBI $\quad$ (95\% CI) & NNT (CI) \\
\hline 15 days & $70 \%$ & $52 \%$ & $35 \%(10$ to 67$)$ & $5(3$ to 17$)$ \\
6 weeks & $51 \%$ & $34 \%$ & $48 \%(9$ to 101$)$ & $6(4$ to 26$)$ \\
3 months & $37 \%$ & $25 \%$ & $48 \%(1$ to 119$)$ & $8(4$ to 393$)$ \\
6 months & $31 \%$ & $16 \%$ & $96 \%(21$ to 221$)$ & $6(4$ to 22$)$ \\
1 year & $27 \%$ & $11 \%$ & $148 \%(40$ to 348$)$ & $6(4$ to 16$)$ \\
6 years & $16 \%$ & $8 \%$ & $92 \%(-5$ to 291$)$ & Not significant \\
\hline
\end{tabular}

*Abbreviations defined in glossary; RBI, NNT, and CI calculated from data in article.

Sources of funding: Pharmacia and Upjohn

For correspondence: Dr T Blondal, Reykjavik Health Care Centre, Baronstigur 47, 101 Reykjavik, Iceland. Fax +3545622415

Abstract and modified commentary also published in ACP Journal Club.

\section{Commentary}

Despite higher cigarette prices, tougher anti-smoking laws, and attempts to hold tobacco companies responsible for smoking related medical costs, smoking cessation remains a huge public health challenge. Blondal et al point out that nicotine patch treatment alone gives an abstinence rate of only $11 \%$ after 1 year. Such results have prompted the search for better single or combination smoking cessation treatments, including combined nicotine patch and spray. Unlike previous studies, Blondal et al followed up patients for an extended period of 6 years. Within the first year, the combination treatment led to a higher abstinence rate than did the patch and placebo spray. Few patients used the spray for up to 1 year. Combination treatment showed a trend toward a higher abstinence rate at 6 years, which suggests a possible long term benefit.

It is unclear whether the higher success rate of combination treatment was because of higher sustained concentrations of nicotine or a brief effect on concentration of the spray delivery system. The spray provides a "quick" dose of nicotine that may relieve temporary cravings associated with relapse of smoking.

Nicotine replacement therapy is one approach to smoking cessation management. Mood is closely related to nicotine consumption. The antidepressant, bupropion, has been shown to be an effective smoking cessation aid. ${ }^{1}$ In their well designed, double blind, controlled trial, Jorenby et al showed that bupropion, used either alone or in combination with the nicotine patch, was more effective than the patch alone or placebo for smoking cessation. A direct comparison of the 1 year continuous abstinence rates across the 2 studies shows interesting results: the rate for the patch spray combination in the study by Blondal et al was $27 \%$, which is similar to that for bupropion alone (18.4\%) or the bupropion patch combination $(22.5 \%)$ in the study by Jorenby et al. Unlike Blondal et al, Jorenby et al followed up patients for 1 year. The continuous abstinence rate beyond 1 year still needs to be studied. The fact that such high intermediate term continuous abstinence rates can be achieved, however, should prompt physicians to consider bupropion in addition

(continued on page 74) 


\title{
Bupropion alone or with a nicotine patch increased smoking cessation rates
}

\author{
Jorenby DE, Leischow SJ, Nides MA, et al. A controlled trial of sustained-release bupropion, a nicotine patch, or both for smoking \\ cessation. $N$ Engl J Med 1999 Mar 4;340:685-91.
}

\section{Question}

What is the relative effectiveness of bupropion, a nicotine patch, placebo, and bupropion plus a nicotine patch for smoking cessation?

\section{Design}

Randomised, double blind, placebo controlled trial with 1 year follow up.

\section{Setting}

4 centres in the US.

\section{Participants}

893 people $\geqslant 18$ years of age (mean age 43 y, $52 \%$ women) who weighed $\geqslant 100 \mathrm{lb}(\geqslant 45.4 \mathrm{~kg})$, were motivated to stop smoking, and who smoked $\geqslant 15$ cigarettes/day. Exclusion criteria included serious physical or psychiatric illness, pregnancy, lactation, and previous nicotine replacement therapy. Follow up was $80 \%$.

\section{Intervention}

Patients were allocated to 9 weeks of either sustained release bupropion, $150 \mathrm{mg}$ /day for days 1 to 3 and $300 \mathrm{mg}$ /day for days 4 to $63(\mathrm{n}=244)$; nicotine patch, $21 \mathrm{mg}$ /day for weeks 2 to 7,14 $\mathrm{mg}$ /day for week 8 , and $7 \mathrm{mg}$ /day for week $9(\mathrm{n}=244)$; or bupropion plus a nicotine patch $(\mathrm{n}=245)$; or placebo $(\mathrm{n}=160)$. Patients stopped smoking on day 8 and received counselling for 1 year.

\section{Main outcome measures}

Self reported point prevalence rate of abstinence in the previous 7 days and carbon monoxide $\leqslant 10 \mathrm{ppm}$, and rate of continuous abstinence (abstinence from quit date and carbon monoxide $\leqslant 10 \mathrm{ppm}$ ); withdrawal symptoms; and weight gain.

\section{Main results}

Analysis was by intention to treat. At 1 year, compared with the placebo and nicotine patch alone groups, the bupropion groups had higher point prevalence and continuous abstinence rates $(\mathrm{p}<0.001)$ (table); no difference existed between the 2 bupropion groups $(\mathrm{p}=0.22$ and $\mathrm{p}=0.61$, respectively). All 3 active treatments led to less severe withdrawal symptoms than placebo in the first 3 weeks $(\mathrm{p}<0.05)$. Bupropion plus a nicotine patch led to less weight gain than bupropion alone or placebo in the first 7 weeks $(\mathrm{p}<0.05)$

\section{Conclusion}

Compared with placebo or a nicotine patch alone, bupropion alone or with a nicotine patch increased the point prevalence and continuous smoking cessation rates after 1 year.

Comparison of smoking cessation regimens for point prevalence or continuous abstinence at 1 year*

\begin{tabular}{|c|c|c|c|c|c|}
\hline Abstinence & Regimen & Intervention & $P$ & $R B I$ & $N N T(C I)$ \\
\hline $\begin{array}{l}\text { Point } \\
\text { prevalence }\end{array}$ & $\begin{array}{l}\text { Bupropion } \\
\text { Combination } \dagger\end{array}$ & $\begin{array}{l}30 \% \\
36 \%\end{array}$ & $\begin{array}{l}16 \% \\
16 \%\end{array}$ & $\begin{array}{c}94 \%(31 \text { to } 193) \\
127 \%(54 \text { to } 240)\end{array}$ & $\begin{array}{l}7(4 \text { to } 16) \\
5(4 \text { to } 9)\end{array}$ \\
\hline Con & $\begin{array}{l}\text { Bupropion } \\
\text { Combination } \dagger\end{array}$ & $\begin{array}{r}18 \% \\
22 \%\end{array}$ & $\begin{array}{l}6 \% \\
6 \%\end{array}$ & $\begin{array}{l}228 \%(69 \text { to } 548) \\
229 \%(108 \text { to } 681)\end{array}$ & $\begin{array}{l}8(5 \text { to } 1 \\
6(4 \text { to } 1\end{array}$ \\
\hline
\end{tabular}

*Abbreviations defined in glossary; RBI, NNT, and CI calculated from data in article and from data provided by the author. †Combination regimen $=$ bupropion plus a nicotine patch.

Source of funding: Glaxo Wellcome.

For correspondence: Dr D E Jorenby, 1300 University Avenue, Room 7278 MSC, Madison, WI 53706, USA. Fax +1 6082653102

Abstract and modified commentary also published in ACP Journal Club. (commentary continued from page 73)

to or as an alternative to, nicotine replacement therapy.

Patients in both studies were highly motivated and received adjunctive supportive counselling. These circumstances may not apply to a larger population of people who smoke and have some desire to stop. Extensive supportive counselling is time consuming, expensive, and difficult to obtain without access to properly trained professionals. The feasibility and success of these treatments in usual ambulatory care settings needs to be determined.

Another important question that has yet to be addressed is the effectiveness of antidepressants other than bupropion for smoking cessation. With nicotine replacement therapy already available in patch, spray, and gum forms, evidence of the effectiveness of other mood altering drugs will add to the smoking cessation management choices available to patients and physicians.

It was the connection between mood and smoking that led eventually to the trial of the antidepressant bupropion as a cessation aid. People with negative affect are more likely to start smoking and less likely to give up. ${ }^{2}$ Affective symptoms are more common among smokers, and their severity is related to the degree of nicotine dependence. ${ }^{3}$

Although it is unclear how the cessation aids assessed in these 2 studies would perform in a mental health care environment, bupropion could obviously have a dual role among patients with major depression as both an antidepressant and cessation aid. The overall positive effect of cessation aids in the mental healthcare environment may actually be greater than in the general population because smoking is very common among people with psychiatric illness.

\section{Goutham Rao, MD University of Pittsburgh Medical Center-St Margaret Pittsburgh, Pennsylvania, USA}

1 Hurt RD, Sachs DP, Glover ED, et al. A comparison of sustained-release bupropion and placebo for smoking cessation. $N$ Engl J Med 1997;337:1195-202.

2 Glassman AH, Covey LS. Smoking and affective disorder. Am J Health Behav 1996;30:279-

3 Anda RF, Williamson DF, Escobedo IG, et al. Depression and the dynamics of smoking. A Depression and the dynamics of smoking. A
national perspective. JAMA 1990;264:1541-5. 